\title{
PROPOSITIONAL OR NON-PROPOSITIONAL ATTITUDES?
}

[Please cite published version: Philosophical Studies 168.1 (2014): 179-210.]

\author{
Sean Crawford \\ University of Manchester \\ sean.crawford@manchester.ac.uk
}

\begin{abstract}
Propositionalism is the view that intentional attitudes, such as belief, are relations to propositions. Propositionalists argue that propositionalism follows from the intuitive validity of certain kinds of inferences involving attitude reports. Jubien (2001) argues powerfully against propositions and sketches some interesting positive proposals, based on Russell's multiple relation theory of judgment, about how to accommodate "propositional phenomena" without appeal to propositions. This paper argues that none of Jubien's proposals succeeds in accommodating an important range of propositional phenomena, such as the aforementioned validity of attitude-report inferences. It then shows that the notion of a predication act-type, which remains importantly Russellian in spirit, is sufficient to explain the range of propositional phenomena in question, in particular the validity of attitude-report inferences. The paper concludes by discussing whether predication act-types are really just propositions by another name.
\end{abstract}

According to propositionalism, the attitude expressed by sentences of the form ' $\mathrm{S}$ believes/hopes/fears/etc. that p' is a relation between a subject and a proposition. Propositionalists maintain that beliefs (and various other psychological states) are attitudes to propositions, that they are propositional attitudes. ${ }^{1}$ Proponents of propositionalism have offered a number of arguments for the view, one of which hinges on the claim that propositionalism follows from the validity of certain kinds of inferences involving sentences that report beliefs and other attitudes. One class of such inferences involves quantified attitude reports. It is alleged, for example, that the inference from 'Maggie believes that Philip is reading' and 'Tom believes that Philip is reading' to 'There is something which Maggie and Tom both believe' is formally valid and that its formal validity implies that the second sentence quantifies over a proposition. The propositionalist gives the argument the following simple and clearly valid first-order quantificational form: $F a b, F c b$, therefore $\exists x(F a x \& F c x)$. What else could the denotation of $b$ and the value of $x$ be but a proposition?

Reflecting on this line of thought, Stephen Schiffer has claimed that one can infer propositionalism "only after it has been established that the quantification here ('there is something which') is to be read objectually rather than substitutionally" (1987,

\footnotetext{
${ }^{1}$ Many propositionalists also accept the linguistic thesis that in a sentence such as 'Maggie believes that Philip is reading' (or 'Maggie fears/hopes/wishes/etc. that Philip is reading'), the 'that'-clause 'that Philip is reading' is a singular term designating the proposition that Philip is reading. Not all propositionalists, however, accept the linguistic thesis. Tobias Rosefeldt (2008), for example, maintains that 'that'-clauses are not singular terms but nevertheless have propositions as their semantic values.
} 
p.8) — and this, in turn, because "only objectual quantification carries 'ontological commitment"' (ibid., p. 274n10). ${ }^{2}$ Recent work by Michael Jubien (2001), however, casts doubt on the idea that objectual quantification is sufficient to deliver propositionalism. Propositionalism does not follow simply from the quantification being objectual. The reason for this, according to Jubien, is that since propositionalism states that the complement clause of a belief report is a singular term designating a single entity, propositionalism only follows from the quantification being objectual if it can be further established that the objectual quantification in question is singular rather than plural. ${ }^{3}$ And Jubien claims that the quantification in question can be given a plural reading (2001, p. 57). While a singular (objectual) quantifier quantifies over a single entity that is believed, namely, a proposition, a plural quantifier quantifies over a plurality of entities to which the subject is belief-related, namely, propositional constituents or relata-with the proviso that propositional constituents or relata, in order to be so-called, need not be constituents or relata of any propositions (Jubien suggests calling them "would-be propositional" constituents).

Jubien's two objectives are, first, to justify rejecting propositions by directing some pretty destructive criticisms their way (pp. 48-54), and, second, more constructively, to "suggest how we may accommodate various 'propositional' phenomena without benefit of propositions" (p. 47). ${ }^{4}$ I shall here be concerned chiefly with Jubien's second positive proposals (pp. 55-61) because, unlike his negative critique of propositions, they have received no critical attention and yet

\footnotetext{
2 Cf. Jerry Fodor (1978), who remarks on the apparently valid inference from 'John believes it's raining' to 'There is something that John believes', that existential generalization "may not be criterial for ontological commitment, but it is surely a straw in the wind" (p. 179).

3 Jubien does not explicitly discuss Schiffer's claim but his appeal to plural quantification implies that Schiffer's argument from objectual quantification to propositionalism is a non sequitur. But see the final section for further relevant discussion.

4 Jubiens's first argument against propositions is that it is impossible to explain how propositional constituents are ordered in the proposition in the right way, that is, for example, in a way that guarantees that $a$ believes all dogs bark rather than believing all barkers are dogs. This "very general, sophisticated coding problem" (p. 53) is "eerily reminiscent" (p. 52) of the notorious "Benaceraff problem" (named after Benaceraff's (1965) influential argument again the reduction of numbers to sets). Jubien's second argument, which really lies at the heart of the first, is effectively that propositions are impossibly supposed to be intrinsically representational. I return to these arguments briefly the final section VI below.
} 
seem to me both interesting and powerful but also in need of far more extensive development than he offers if they are to be considered at all satisfactory. ${ }^{5}$

As we have just seen, one of these "propositional phenomena" that is in need of accommodation is the alleged fact that the validity of certain intuitively valid arguments involving quantified attitude reports relies on quantification over propositions. I will argue first that Jubien has not succeeded in showing how to read such quantifications plurally, because he has not succeeded in showing how such plural quantifications can be used to deliver the validity of the intuitively valid arguments in which they figure as premises. It follows that he has not fulfilled his promise of showing how to accommodate without propositions one of the most central of propositional phenomena. Luckily, two further features of Jubien's viewthe notion of a "belief-property" and the fact that such properties can be quantified over-offer a much more promising approach. Unfortunately, while more promising than the appeal to plural quantification, this approach too suffers from some serious defects and must ultimately be rejected. I will argue, however, that the spirit behind the failed property theory can be developed into an account that succeeds, one that I call the predication theory. The central innovation of the predication theory is to replace Jubien's ultimately problematic notion of a belief-property - more generally, an intentional-property (a determinable with the determinates belief-property, hopeproperty, etc.) - with the notion of a predication act-type. The predication theory, unlike Jubien's property theory, can be used to fulfil the promise to account for the validity of the arguments deemed by propositionalists to support their view. However, the interpretation of this result is not as dialectically straightforward as it might at first seem and this fact points to a problematic ambiguity surrounding the notion of a proposition as it figures in the current rather murky debate over the existence of propositions. It might initially seem as if the way to interpret the result is to hold that Schiffer's argument from objectual quantification to propositionalism is nevertheless still a non sequitur because of the possibility of quantifying over something other than propositions - namely, predication act-types - in order to account for the validity of the arguments in question. In other words, even if the (objectual) quantification is singular (rather than plural) propositionalists must still

\footnotetext{
5 Jubien fully admits the sketchy character of his positive proposals. For a critical but sympathetic discussion of Jubien's negative case against propositions, see King (2007), pp. 129-136.
} 
show that this single object is a proposition and not something else, given that there is now an alternative candidate for this single entity, namely, a predication act-type. ${ }^{6}$ However, as we shall see, self-styled propositionalists may be able to do this all too easily, simply by declaring that this alleged alternative, a predication act-type, is only allegedly an alternative and in fact just is a proposition by another name. It is important to recognize, however, that this manoeuvre, resting as it does on an allegiance to a metaphysically neutral and purely functionalist conception of propositions, does nothing to re-instate the kind of metaphysically loaded conception of propositions - "Platonic propositions" - that is the target of Jubien's attack.

Jubien's proposal begins by treating belief and other attitudes as multigrade relations that may hold between a subject and an arbitrary number of propositional constituents, which for him are always properties and relations. ${ }^{7}$ He illustrates the idea with the example of $a$ 's believing that all dogs bark. On the multigrade view, to say that $a$ believes that all dogs bark is to say that a believes being a dog to be subextensive to barking (p. 56). This, in turn, is to say that the relation of believing holds between the subject, the property of being a dog, the property of barking and the relation of subextensiveness. Jubien represents this "in standard first-order fashion" as: $\operatorname{Bel}(a, d, s, b)$-letting, he says, the order of the non-logical constants conventionally "capture" the specific way that $\mathrm{Bel}$ holds among these propositional constituents. ${ }^{8}$ There are two important further features of the account, described by Jubien as follows: "The picture grants to $a$ the ability to be related intentionally to

\footnotetext{
6 On this interpretation, the predication theory thus counts as an unconsidered alternative to the four theories mentioned by Richard (1996, p. 437).

7 Jubien notes the similarity to Russell's (1910) multiple-relation theory of belief (or judgment), which has been receiving a significant amount of renewed attention recently after many years of neglect. It should be noted, however, that it was Quine (1977), strictly speaking, who originally proposed to treat 'belief' as a multigrade predicate (at least so described, for Quine (1977) says the multigrade approach was already present in Quine (1956) even though it is not described as such in the latter). It should be noted further that, unlike both Quine and Russell, Jubien does not allow individuals as propositional constituents. This has no bearing on any issue under discussion here and I will assume that individuals can be propositional constituents (or would-be propositional constituents). I discuss Quine's multigrade account of attitudes at length, defending it against objections that could also be leveled at Jubien's version, in Crawford (2008).

$8 \mathrm{He}$ also notes that the same kind of first-order symbolization will be given to a range of other attitude reports: " $a$ 's hoping that some dogs don't bark might be represented by ' $H(a, d, c, n o t-b)$ ' with $H$ for hope and $c$ for coinstantiation, etc." (ibid.).
} 
each of the three 'constituents' and, again intentionally, to take one of them as relating the others in a particular way (ibid.)." Remarking on the first feature, Jubien says that it "makes it look like the attribution of a belief to $a$ that is de re with respect to the two properties and subextensiveness. This is a picture I would like to encourage but without explaining just how it is that we become connected mentally to properties and relations." I will assume, with Jubien, that the view under development is a one according to which the attribution of belief and other intentional attitudes is de re with respect to the propositional constituents involved, without explaining how the de re connection to the constituents is set up. ${ }^{9}$ The second feature, according to Jubien, should be understood as crediting subjects with "the intentional ability to hook together the constituents in the right way" and he speaks of subjects as "directly applying" the "logical glue" to the propositional constituents (in the right way). ${ }^{10}$

Jubien is quite right that the subject's intentional ability to knit together propositional constituents in the right way is an absolutely crucial part of the theory. As we shall shortly see, however, the exact role that this notion needs to play in the theory causes Jubien some trouble. As we have just seen, he suggests that the notion does not figure explicitly as a constituent in the logical form of the attitude report; rather, the notational order of the symbols that represent the constituents is to be taken as conventionally representing the way in which the subject orders them. But the propositional phenomena of concern here, namely, inferences involving (sometimes quantified) attitude reports, seem to demand some kind of explicit reference to intentional ordering. In order to see this, let us turn to an initial problem posed for the multigrade theory.

\section{II}

As Jubien notes, the proposal as it stands faces a rather serious problem, for it appears to leave us without a way of expressing quantified belief reports, such as 'Bill believes everything Hillary does'. The second part of Jubien's multigrade proposal is to use plural quantification to do so (which is anyway a natural companion to multigrade predication). The basic idea is that where the propositionalist quantifies

\footnotetext{
9 But see note 31 below.

10 Thus sidestepping the first "devastating problem" facing propositionalism, mentioned in note 4 above.
} 
singularly over propositions the multigrade theorist will quantify plurally over propositional relata. Rather than go into the details of plural quantification, Jubien relies on the "intuitive clarity" of the notion, and proceeds to "announce the solution to [the] problem as follows: For any propositional relata, if Hillary stands in the belief relation to them in any specific way, then so does Bill” (p. 57). It is easy to see how the proposal may be extended to express existentially quantified belief reports, such as 'There is something Maggie and Tom both believe'. A plural quantificational reading would be: 'There are some propositional relata to which both Maggie and Tom are belief-related in a specific way'. We have then, it seems, a way of expressing quantified belief reports without quantifying over propositions. So far so good.

But this is only half a solution to the problem. For as we have seen, quantified belief reports figure in intuitively valid arguments and the propositionalist claims that their intuitive validity implies - or anyway gives overwhelming reason to believe in — the existence of propositions. Let us then insert Jubien's example as a premise in an intuitively valid argument and see whether the multigrade proposal, supplemented with plural quantification, can, as promised, accommodate the "propositional phenomenon" of validity, without the benefit of propositions. Here is such an argument:

(A)

Hillary believes that all dogs bark.

Bill believes everything Hillary does.

So, Bill believes that all dogs bark.

Now, how does rendering the second premise as an instance of plural quantification $\grave{a}$ la Jubien's proposal, deliver the validity of this argument? Given the foregoing details, the non-propositional multigrade approach is presumably to be written out informally in English as:

Hillary believes being a dog to be subextensive to barking.

For any propositional relata, if Hillary stands in the belief relation to them in any specific way, then so does Bill.

So, Bill believes being a dog to be subextensive to barking. 
There is an immediate problem with this, however. While Jubien has told us how to render the first premise and the conclusion "in standard first-order fashion," he has not told us how to do the same for the second premise. So far-letting ' $w$ ' stand for Bill (William) so as not to collide with ' $b$ ' for barking - we just have the incompletely symbolized argument:

(B)

\section{$\operatorname{Bel}(h, d, s, b)$}

For any propositional relata, if Hillary stands in the belief relation to them in any specific way, then so does Bill.

Therefore, $\operatorname{Bel}(w, d, s, b)$

On the face of it, it looks like no matter what symbolization Jubien gives for the second premise - whether or not the symbolization in question is "in standard firstorder fashion" - argument (B) is going to come out formally invalid. There are two reasons for this. First of all, the second premise contains a quantification over propositional relata but there is no such term 'propositional relata' in either the first premise or the conclusion, so modus ponens cannot be (validly) applied after universal instantiation on the second premise. Secondly, the second premise contains a (universal) quantification over specific ways of being belief-related to propositional relata; again, however, no such term 'standing in a belief-relation in a specific way' occurs in the first premise or in the conclusion, so the required rules of inference again cannot be (validly) applied.

We have already seen that the propositionalist has an easy time of it. He will give (A) the simple valid first-order quantificational form: $F a b, \forall x(F a x \rightarrow F c x), F c b$. The question, then, is whether the first premise and conclusion of (B), as interpreted by Jubien's non-propositional multigrade theory, can be altered so that the second premise connects with them in a way that makes the argument come out valid. Can this be done? Let us explore what this would involve. Rather than build the term 'propositional constituent' explicitly into the first premise and into the conclusion of (B), thereby adding cumbersome and undesirable complexity not present in the original vernacular statements, let us simply drop it from the second quantified premise, giving the simpler: 'For any things, if Hillary stands in the belief relation to them in any specific way, then so does Bill'. After all, just as the propositionalist 
need not explicitly say in his symbolization that what is quantified over is a proposition, in order to account for the validity of the argument, so too neither need the multigrade theorist say explicitly in his symbolization that what is quantified over are propositional constituents, in order to account for the argument's validity.

The second premise of (B) still makes reference, however, to a specific way of being belief-related. And this cannot be elided along with the previous reference to propositional constituents, for it is absolutely crucial to the validity of the argument. To see this, look at what happens when it is removed. The informal English version is easy:

Hillary believes being a dog to be subextensive to barking.

For any things, if Hillary stands in the belief relation to them, then so does Bill.

Therefore, Bill believes being a dog to be subextensive to barking.

The formal version, using ' $x x$ ' as notation for a plural variable bound by a (universal) plural quantifier is also straightforward:

(C)

$\operatorname{Bel}(h, d, s, b)$

$\forall x x /(\operatorname{Bel}(h, x x) \rightarrow \operatorname{Bel}(w, x x)]]$

Therefore, $\operatorname{Bel}(w, d, s, b)$

Unfortunately, argument (C) is not valid: it is possible for its premises to be true and its conclusion false. A counter-example is the situation in which Hillary believes being a dog to be subextensive to barking but Bill does not believe this and instead believes the reverse, namely, barking to be subextensive to being a dog (or, as the propositionalist would say, that all barkers are $\operatorname{dog} s)$, that is, $\operatorname{Bel}(w, b, s, d)$. Recall that in the first premise and in the conclusion we are, following Jubien's explicit instructions, using the typographical order of the non-logical constants as a notational device for representing the specific way that a person is belief-related to the propositional constituents designated by those very constants. As Jubien himself emphasizes, believing being a dog to be subextensive to barking is to bear a beliefrelation to the same propositional constituents as believing barking to be subextensive to being a dog-but to do so in a different way. In short, Bel( $w, d, s, b)$ is different from $\operatorname{Bel}(w, b, s, d)$ even thought they both relate their subjects to the very 
same propositional constituents. Since all that the second premise of (C) says is that Hillary and Bill are belief-related to the same plurality of things, it does not distinguish between being belief-related to different orderings of that same plurality, between, for example, $\operatorname{Bel}(w, d, s, b)$ and $\operatorname{Bel}(w, b, s, d)$. Although Jubien is correct that "the plural quantifier finesses the belief relation's lack of a specific index," that is, its lack of a fixed adicity, it does not finesse (if that is the right word) the belief relation's ordering of the propositional constituents. The plural quantifier quantifies over a simple unordered plurality (which the overall sentence then says is such that Hillary and Bill both are both belief-related to it). But the first premise and the conclusion of (B) both relate their subjects to a specific ordering of that plurality. In short, we cannot conclude that Bill believes being a dog to be subextensive to barking rather than the other way around. Argument (C) is invalid. ${ }^{11}$

Now, as we have seen, Jubien is manifestly aware of the need for propositional constituents to be ordered in a specific way. On his view, it is the individual subject who intentionally brings this ordering about. While Jubien himself makes no mention of the notion at all, the intentional ordering should, I think, be understood as being brought about by a mental act of predication. This mental act of predication, which applies the "logical glue" to the propositional constituents in the right way, is captured in the symbolism of a non-quantified belief report by the left-to-right typographical ordering of the individual non-logical constants. But this device is not available for use in the plurally quantified sentence precisely because there are no ordered constants there but only a plural variable whose value is an unordered plurality (of propositional constituents). This is why a reference to a specific way of ordering this plurality is required in the second quantified premise of (B) and why Jubien explicitly includes it. The premise of must read: 'For any things, if Hillary stands in the belief relation to them in any specific way, then so does Bill'.

But how are we to render this premise symbolically in a way that makes (B) formally valid? Moreover, how are the respective symbolizations of the first premise and the conclusion of (B) to be correspondingly altered so as to mesh with the quantified second premise's critical reference to a specific way of being belief-

\footnotetext{
11 I am grateful to Friederike Moltmann for correspondence (in 2006) which inspired this paragraph. Her own non-propositional theory (Moltmann 2003) is, like Jubien's and mine, inspired by Russell's multiple-relation theory.
} 
related? Can the anti-propositional multigrade theorist match the rigorous standards of the propositionalist here and supply a formally valid logical form? ${ }^{12}$ It is not entirely clear that he can. The task, at any rate, appears to be a difficult one, and if it can be carried off at all, will most likely result in a very complex logical from, crucially one far more complex than the propositionalist's, thus ruling it out on grounds of lack of simplicity. Be that as it may, I will simply lay it down as a challenge to the non-propositionalist who favours plural quantification and leave the point moot - for Jubien seems to have another interesting card in his deck which suggests that he may not anyway be dialectically required to carry off this particular plural symbolization exercise.

\section{III}

Jubien asks, "But what is it to stand in the belief relation to some propositional relata in a specific way?" (p. 58), suggesting that he is sensitive to the above problem and to the fact that a solution to it requires some way of factoring in a "way of relating propositional constituents." He seems to think that the way to do this is to bring in the notion of a "belief-property." The idea is best illustrated with an example. If you

12 Schiffer (2003) is curiously inconstant about invoking the requirement that verdicts of prima facie intuitive, informal validity be backed up formally. On the one hand, he seems to demand it when it comes to the kinds of allegedly intuitively valid arguments involving propositional attitudes we have been looking at, which form the basis for what he calls the "face value theory" of belief reports, for he specifies their formally valid logical forms (pp. 12-13). On the other hand, when it comes to his own preferred theory of "pleonastic propositions," and the alleged intuitive validity of what he calls "something-from-nothing transformations" on which it rests, some of which involve precisely the same question of reference to propositions, he apparently takes a more relaxed view. He says (on p. 61) that from a statement such as 'Lassie is a dog', we can "validly infer the pleonastic equivalent," namely, 'Lassie has the property of being a dog', which, he claims, "contains a new singular term 'the property of being a dog', whose referent is the property of being a dog." He says further that one can also validly infer 'That Lassie is a dog is true', in which 'That Lassie is a dog' is singular term whose referent is the proposition that Lassie is a dog. But he fails to specify the logical form of these inferences according to which they are formally valid. Unlike the previous propositional-attitude inferences, these "something-from-nothing" deductions (or equivalences) are not formally valid in the standard first-order predicate calculus which is used to show the formal validity of the previous arguments that allegedly support the face value theory. It is not clear whether Schiffer takes them to be formally valid at all. He does not anyway say what kind of logic he has in mind according to which they are formally valid, if he thinks they are. Nor does he explain why, if he views them as not formally valid, he is prepared to maintain nevertheless that they are informally valid, seemingly contrary to his earlier treatment of face-value-theory inferences involving propositional attitudes. He does say that what explains the (intuitive?) validity of the something-from-nothing transformation 'Lassie is a dog; therefore, Lassie has the property of being a dog', is that "it is a conceptual truth that if Lassie is a dog, then Lassie has the property of being a dog' (ibid.). But if he is prepared to rest the explanation of the validity of something-from-nothing transformations here, at the level of "conceptual truth," and not press for a formal explanation, then why demand the stronger requirement for the propositional-attitude inferences alleged to support the face value theory? 
believe being a dog to be subextensive to barking then you have a certain relational property, says Jubien — namely: believing being a dog to be subextensive to barking. ${ }^{13}$ This is a belief-property and it is a different belief-property from believing barking to be subextensive to being a dog. To say that someone is belief-related to some propositional constituents in a specific way is, then, to say that they have a specific belief-property. Applied to the situation at hand, Jubien says that "we may compress the solution to the Hillary-Bill problem as follows: For any belief property, if Hillary has it, then so does Bill" (ibid.). He then concludes by hoping that "it seems reasonable to think the multigrade approach might be exploited to account for the full range of propositional-attitude phenomena without appealing to propositions" (ibid.).

Unlike the use of plural quantification discussed above, whose ultimate success seems highly dubitable, this seems a more promising way to give an account of the formal validity of arguments containing quantified belief reports. Again, however, since Jubien does not himself give such an account of the validity-he lets the matter rest with his belief-property version of the quantified belief report and does not attempt to show how it interacts with other reports in valid inferences-we do not know what form he thinks such an account would take. But such an account is necessary to accommodate all "propositional phenomena" without propositions and so to counter propositionalism. In the rest of this section I will show how, with beliefproperties at our disposal, we no longer require plural quantification in order to give an account of the validity. It will turn out, however, in section IV, that the beliefproperty approach faces some serious problems of its own. Section V is given over to developing a replacement of the property theory that I call the predication theory, which is, I think, a better way of solving the ordering problem.

Let us first lay the argument out informally:

(D)

Hillary has the belief-property believing being a dog to be subextensive to barking. For any belief property, if Hillary has it, then so does Bill.

So, Bill has the belief-property believing being a dog to be subextensive to barking.

13 As Jubien notes (p. 62n15), a whole range of intentional properties will be needed, including, e.g., hope-properties and fear-properties, so that, to revert to his earlier example (see previous note 8), $a$ 's hoping/fearing that some dogs don't bark is to possess the hope-property/fear-property hoping/fearing being a dog to be co-instantiated with not-barking. 
How is this to be symbolized as formally valid? Given that we need to quantify over belief-properties, pursuing a propositionless first-order symbolization implies that

belief-properties should be among the values of the (first-order) variables bindable by (first-order) quantifiers. ${ }^{14}$ If so, it follows that belief-properties must be designated,

14 Contrary to what Moore (1999, p. 251) claims, it is simply not true that on a view according to which intentional contents (whether taken as propositions or not) are construed as properties rather particulars (the "predicative re-interpretation" view, as he calls it), quantified attitude reports will require second-order quantification over properties. One can, as Jubien does, simply take the properties in question to be values of first-order variables bindable by first-order quantifiers, just as propositionalists standardly take propositions to be. Indeed, on one common understanding, propositions, properties and relations are all the same kind of logical entity, namely, $n$-place intensions, propositions being limiting-case 0-place intensions or "closed attributes" (cf. Quine (1960), p. 165; Bealer (1982, p. 30)). Nevertheless, it should be noted that a symbolization using second-order quantification, were it required, is easily given and - again pace Moore (loc. cit.) — is hardly very complicated. Combining second-order quantification with second-order properties (i.e., properties of properties), we might pursue the following symbolization. Using ' $\mathrm{P}$ ' to stand for the (first-order) belief-property believing being a dog to be subextensive to barking, ' $\mathrm{B}$ ' for the (second-order) property of being a belief, ' $h$ ' for Hillary, and ' $b$ ' for Bill, argument (D) can formalized thus:

$P h \& B(P)$

$\forall X[(X h \& B(X)) \rightarrow(X b)]$

Therefore, $P b$.

Returning to the validity of the argument discussed at the outset, which has an existentially quantified conclusion, we can see that it can be handled in a similar fashion. In the vernacular, the argument is:

Maggie believes that Philip is reading.

Tom believes that Philip is reading.

So, there is something which Maggie and Tom both believe.

Translated into the language of belief-properties, we get:

Maggie has the belief-property believing Philip to be reading.

Tom has the belief-property believing Philip to be reading.

So, there is some belief-property that Maggie and Tom both have.

Using ' $\mathrm{m}$ ' for Maggie, ' $\mathrm{t}$ ' for Tom, 'P' for the (first-order) belief-property believing Philip to be reading, and ' $\mathrm{B}$ ' again for (second-order) belief, we have:

$P m \& B(P)$

$\underline{P t}$

Therefore, $\exists X[(X m \& X t) \& B(X)]$

This is itself enough to show that Jubien's non-propositional belief-property approach can be extended to provide simple and straightforward valid symbolizations of the kind of intuitively valid arguments we have been dealing with. But is it enough to counter propositionalism? The propositionalist might well argue that it is not, on the grounds that the second-order logic it uses lacks various desirable metalogical properties possessed by the first-order logic of the propositionalist (e.g., completeness and compactness). All things being equal, surely a first-order symbolization is preferable, if it is available. It is available and all things are equal - so the propositionalist still wins the day. Cf. Bealer (1982), p. 32. The belief-property theorist might protest that all things are not equal. A second-order symbolization cannot be trumped, he might say, by a first-order one that appeals to propositions, simply on the grounds that the former suffers from various metalogical shortcomings that the latter does not, because the existence of propositions is precisely what is in dispute. The sacrifice of some of the metalogical properties of first-order logic is worth it, in other words, if the payoff is an account of 
not by predicate letters, but rather by individual constants or names, as the classic rules of inference, such as universal and existential instantiation, depend on this. This much, of course, is also part of the propositionalist's view: propositions - the propositionalist's counterparts to the property theorist's belief-properties - are named by individual constants in logical forms and are the values of variables. The propositionalist takes 'believes' to be a dyadic predicate, symbolizing 'Hillary believes all dogs bark' as ' $B h p$ ', in which the positions occupied by ' $h$ ' and ' $p$ ' can be replaced by bound variables. On this basis, the propositionalist is able to represent the universally quantified belief report 'Bill believes everything Hillary does' as: ' $\forall x(B h x \rightarrow B w x)$ '. On the property-theory proposal, the constants ' $h$ ' and ' $p$ ' will stand for, respectively, Hillary, on the one hand, and the belief property believing being a dog to be subextensive to barking, on the other. In order for this to work, however, we will need two further, unary predicates, 'is a belief property' and 'has' or 'is possessed by'. Using ' $B$ ' for the former and ' $H$ ' for the latter, and ' $b$ ' for Bill this time, we symbolize 'For any belief property, if Hillary has it, then so does Bill' as : ' $\forall x[(B x \& H h x) \rightarrow(B x \& H b x)]$ '. Correspondingly, we symbolize the first premise of (D) as ' $B p \& H h p$ ', which says: 'Hillary has the belief-property believing being a dog to be subextensive to barking'. The property theorist can interpret argument (A) as (D) and take (D) as having the following valid logical form:

(E)

$B p \& H h p$

$\forall x[(B x \& H h x) \rightarrow(H b x)]$

Therefore, $H b p$

The argument we opened with in the first paragraph, in which Maggie and Tom each believe Philip to be reading, can in turn be formalized as valid thus:

$\underline{B p} \&(H m p \& H t p)$

Therefore, $\exists x[B x \&(H m x \& H t x)]$,

the formal validity of the arguments we have been looking at that does not appeal to propositions. It seems to me, however, that although the property theorist might be able to mount a defense of a second-order approach in this fashion, a stronger strategy is to try to meet the propositionalist on his own logical ground by providing a first-order symbolization, which is what I shall do. 
which says, in English, 'Believing Philip to be reading is a belief property possessed by both Maggie and Tom; therefore, there exists some belief property that Maggie and Tom both possess'. ${ }^{15}$

The property theory seems, then, to be able to provide a simple and straightforward propositionless first-order symbolization on which the arguments we have been considering are formally valid.

\section{IV}

There are strong reasons, however, to doubt the ultimate viability of the property theory. There are (at least) two types of propositional phenomena that it seems unable to accommodate. First of all, as has been pointed out many times before, beliefs can share content with other attitudes. ${ }^{16}$ For example, Tom can believe or doubt or fear or wish that all dogs bark. Moreover, obviously different individuals can have different attitudes to the same content too: Maggie can doubt that all dogs bark while Philip fears it and Bob wishes it. Because the property theory fuses attitude and content into a single object to which the subject bears the single relation of having, it must represent this state of affairs in a way that masks the fact that all four individuals' mental states share the same content, to wit: Tom has (the belief-property) believing being a dog to be subextensive to barking and Maggie has doubting being a dog to be subextensive to barking and Philip has fearing being a dog to be subextensive to barking and Bob has wishing being a dog to be subextensive to barking (symbolized respectively as: Htp \& Hmq \& Hpr \& Hbs). Furthermore, there are of course such "mixed" attitude scenarios whose accurate description involves quantification over a single shared content toward which different attitudes are reported to be taken, either by different individuals — such as 'Maggie believes everything Tom says', 'Maggie believes three of the five things Tom asserted and doubts two of them' and 'Tom

\footnotetext{
15 Jubien's property theory thus shows that sharing beliefs (or more generally sharing the same attitude to the same content) does not itself, pace G. E. Moore (1953, p. 62), demand an act-object analysis of belief. However, as we shall see presently, having different attitudes towards the same shared contents does support a Moorean act-object analysis of belief (and other attitudes).

16 G. E. Moore was perhaps the first to make this absolutely explicit in lectures given in 1910-11 (see Moore 1953, pp. 59-60), even though he mentioned only a fairly restricted range of attitudes, namely, belief, disbelief and understanding (as mentioned in the previous note, he also emphasizes on page 62 that more than one person can believe the same thing). Stich (1983, p. 32) is among many recent philosophers who have since restated the point as allegedly part of a "folk theory" implicit in commonsense psychology.
} 
believes something that Maggie fears' — or by the same individual—as in 'Tom believes everything he reads', 'Tom believes three of the five things he read' and 'Maggie fears something she heard' ${ }^{17}$ The property theory is unable even to symbolize these statements let alone express the validity of inferences in which they appear. This is again because the very idea of an intentional property, such as a belief-property or fear-property, is effectively a fusion of attitude and content (or act and object, in classical terminology) into a single entity that is then quantified over, whereas the symbolization of such quantified mixed-attitude reports precisely requires a fission of attitude from content (act from object) so that only the latter is quantified over. $^{18}$

Secondly, there is class of valid inferences involving both attitude reports and non-attitude reports whose validity the property theory seems incapable of explaining. These can be introduced with the following example:

(F)

Hillary believes that all dogs bark.

That all dogs bark is true.

Therefore, Hillary believes something true. ${ }^{19}$

What is interesting about $(\mathrm{F})$ is that its second premise is not a report of any attitude at all. It is obvious how the propositionalist will symbolize the argument:

17 Such examples go at least as far back as Ayer (1940, pp. 101 and 103). See also the later dispute about them between Quine (1960, p. 211) and Prior (1963, p. 149).

18 Cases that mix belief or knowledge, on the one hand, and either fear or desire, on the other-e.g., the quantified report 'Maggie fears something she knows' ( $\exists x[F m x \& K m x]$ ) — constitute prima facie counter-examples to Trenton Merricks' (2009) strong thesis that belief is always a propositional attitude but desire and fear never are. Part of Merricks' argument for his thesis is that beliefs (and other broadly cognitive states) can be true or false but fears and desires (and other kindred attitudes) cannot and that the truth and falsehood of beliefs derives from the truth and falsity of their propositional objects. It looks on the face of it that his thesis faces a whole class of counter-examples involving (both quantified and unquantified) attitude sentences that report a single shared content toward which a truth-evaluable attitude and a non-truth evaluable attitude are both directed.

19 Cf. Schiffer (2003, p. 12):

Harold believes that there is life on Venus

That there is life on Venus is implausible

So, Harold believes something implausible

It is evident that any predicate applicable to propositions ('false', 'plausible', 'dubitable', 'interesting', 'necessary', 'contingent', etc.) has the potential to generate such an argument. The basic point — that we often say that one and the same thing is both believed by someone and is also true/plausible/etc. has, again, been made many times before in discussions of propositions. Field (1978, p. 37) offers the following nice example: 'There are many things she believes about him, and none of them are at all complimentary'. 
(G)

$B h p$

$T p$

Therefore, $\exists x(T x \& B h x)$.

The proposal in section III above implies that the property theorist will symbolize (F) as:

(H)

Bp \& Hhp

$\underline{T p}$

Therefore, $\exists x[(B x \& T x) \& H h x]$,

which can be translated into questionable English as:

Hillary has the belief-property believing being a dog to be subextensive to barking.

The belief-property believing being a dog to be subextensive to barking is true.

Therefore, Hillary has a true belief-property.

But how can we make sense of the second premise here? What can it mean for a particular belief-property to be true? The problem, moreover, does not stop here, for there is a whole host of further properties traditionally ascribed to propositions such as being necessarily true, being indubitable, being interesting, being plausible, etc. - as well as logical relations traditionally taken to hold between propositions such as entailment, consistency and inconsistency — all of which can figure in valid arguments akin to (F). If belief-properties can possess such properties and stand in such relations, it cannot be because of anything to do with propositions, because there are not supposed to be any propositions, according to the property theorist. Now, we do speak of properties such as colours and shapes being "true of" and "false of" things (philosophers do, at any rate), namely, of those things that instantiate them, and this notion does not invoke propositions. The natural analogue for a complex property that seems to involve a proposition - for example, the property being such that all dogs bark - is to say that it is true when it is true of everything, in other words, when it is instantiated by everything. Roderick Chisholm (1981, p. 7; cf. Chisholm 1976, passim, on states of affairs) and Jubien himself in later work (Jubien 
2009, pp. 92-4) have both offered accounts of property entailment that similarly do not depend on the existence of propositions, according to which (roughly speaking) property $F$ entails property $G$ when anything that instantiates $F$ necessarily instantiates $G$. It is not easy, however, to see how the idea of instantiation can be applied to belief-properties, for it would seem to require that belief-properties be instantiated by things that do not have beliefs, or indeed any mind at all. While it may make sense - at a rather artificial stretch - to say that the property being such that all dogs bark is instantiated by everything, including chairs, trees, crystals and spiral nebulae, we surely do not want to say that the property believing all dogs bark is instantiated by everything, including chairs, trees, crystals and spiral nebulae! The property theorist might of course be able to give an account of how belief-properties can be true, necessary, plausible, etc. that does not have such an absurd consequence. ${ }^{20}$ But, given that he still has to face the previous problem, rather than

20 In the course of defending what he calls the "property theory of content" — aka the self-ascription theory of content, originated independently by David Lewis (1979) and Roderick Chisholm (1981), according to which to believe that $P$ is to self-ascribe the property being such that $P$ - Neil Feit (2008) proposes that while absolute truth does not apply to properties as it does to propositions, "truth talk" nevertheless applies to properties in the sense that they are true of the things that have them and false of things that do not have them. Accordingly, Feit says that "on the property theory, a subject has a true belief (i.e., believes truly) when she self-ascribes a property that she has" (p. 24). He then ingeniously suggests (on p. 112) that the self-ascription property theory can render the argument under discussion (actually, his example is slightly different but not relevantly so) in the following manner:

Hillary self-ascribes being such that all dogs bark. [Shp]

Being such that all dogs bark is true of Hillary. [Tph]

So, there is something that is self-ascribed by Hillary which is true of her. [ $\exists x(S h x \& T x h)]$

It is not clear to me that 'Being such that all dogs bark is true of Hillary' is an adequate substitute for 'The proposition that all dogs bark is true', given that the latter makes no reference to Hillary and has on the face of it nothing whatsoever to do with her and would have truth conditions even if Hillary failed to exist. A better replacement for Feit might be 'Being such that all dogs bark is true of everything $[\forall x T p x)]$ ', and, correspondingly, for the conclusion, 'there is something that is self-ascribed by Hillary which is true of everything [ $\exists x(S h x \& \forall y T x y)]$ ', though I have reservations about these too. Rather than press those concerns here, let me make two points more directly relevant to present purposes. First, whatever its intrinsic merits, Feit's account requires accepting the self-ascription theory, and that is something to which Jubien's property theorist may not wish to be beholden. Second, even if the property theorist (in Jubien's sense) were to embrace the self-ascription theory, it will not help very much anyway. This is because, even if this particular account works for the property of being true (which is somewhat doubtful), it will not work for all — if indeed any — other properties that a propositionalist will say are applicable to propositions and that can figure in the kinds of inferences under discussion, such as is plausible, is interesting, etc.. For, unlike 'true of', there does not seem to be a correlative notion of a property being or failing to be, e.g., "plausible of" or "interesting of" an object, so that being such that all dogs bark could be plausible of, or interesting of, Hillary, in inferences just like the one above but with these latter properties replacing is true.

Feit, perhaps recognizing this, has another proposal that may be supposed to apply to such properties. He considers anyway one example of such a property, namely, an inference involving something that is both believed and necessary: 'Whatever $\mathrm{x}$ believes is necessary; whatever is necessary is true; therefore, whatever $\mathrm{x}$ believes is necessary'. His solution to the problem of how the 
attempt to develop such an account, it seems clear that the property theorist is better advised to find something else that can less controversially be said to bear the properties and relations propositionalists traditionally attribute to propositions. The best thing to do, dialectically speaking, is to find something that the propositionalist agrees the properties of being true and being false (inter alia) can be applied to as well as propositions. For example, the propositionalist will accept that utterances or speech acts, which are events, can be true or false, as well as propositions. ${ }^{21} \mathrm{We}$ know from section II above that this something else to which the properties of being true/false (necessary/contingent, plausible/implausible, etc.) are applicable must also be capable of solving the ordering problem, that is, it must be something that provides for the specific way of believing the pluralities of would-be propositional elements. We know further from what was said at the beginning of this section that this something else must also be detachable from any attitude that might be held toward it. Belief-properties seem to solve the "ordering problem" but in the course of doing so run into the "property problem" and the "shared-content/different-attitude problem." In section II the notion of an intentional ordering relation was mentioned, a relation that Jubien said "glues" or "hooks" propositional relata together in the way that agents with cognitive capacities are able to do (without, as Jubien notes (p. 55), saying exactly how they are able to do this). I suggested there that we understand this intentional ordering relation, which Jubien unsuccessfully attempted to construe as the possession of a specific belief-property (or other specific intentional-property), as being brought about by an act of predication, which forms the basis of judgement and belief. What Jubien refers to as "the intentional ability to hook together the [would-be propositional] constituents in the right way," or "intentionally, to take one of them as relating the others in a particular way," and which he failed to capture with his notion of a belief-property (intentional-property), is, I am suggesting, the ability to perform acts of predication. Like belief-properties, predications are ways of ordering

self-ascription property theory can account for the validity of this inference is that "what someone believes is necessary in the sense that the self-ascribed property corresponds to a necessary proposition, where a property $F$ corresponds to a necessary proposition if and only if there is a necessary proposition $P$ such that $F$ is the property being such that $P$ " (p. 110). On this basis, selfascriptionists can then "simply help [themselves] to the propositionalist's conception of [its validity]" (p. 111). Again, whatever its intrinsic merits, this proposal cannot be accepted by Jubien's property theorist because it assumes precisely what the latter denies, the existence of propositions.

21 Cf. Quine (1986, p. 13): "What are best seen as primarily true or false are ... events of utterance." For propositionalists, propositions are of course best seen as primarily true or false and events of utterance only derivatively so. Jubien (p. 58f) discusses the issue briefly. 
propositional constituents - but unlike belief-properties, predication can be true or false. Although a belief-property is not naturally thought of as being true or false, a predication most certainly is. I can truly and I can falsely predicate a property of an object. Similarly for the other properties that propositionalists ascribe to propositions.

The idea, then, is that what the property theorist needs to appeal to in lieu of propositions as bearers of truth and falsity is a special kind of event akin to an utterance, a special kind of mental act - namely, a type of mental act of predication, or predication act-type, for short. We might say that predication act-types are to the property theory as propositions are to propositionalism. Predication act-types can have the properties of being false, being necessary, being indubitable, being implausible, etc. and can stand in logical relations such as inconsistency and entailment. Presumably the propositionalist will not object to this: he will accept that we can and do perform mental acts of predication which can be true and which can be false; he will just insist that such predications are only derivatively true in virtue of the propositions they express being ultimately true. ${ }^{22}$

Although a predication, like a declarative sentence, has a truth condition, and so is (or at least can be) either true or false, an agent engaging in an act of predication need not accept or endorse the predication, in the same way that when someone is saying or uttering or writing down a sentence he need not be asserting the sentence, in the sense of accepting it as true or assenting to it. Just as not all sayings or utterances or writings of sentences are assertions of (or assentings to) those sentences, so not all predications are judgings or believings. I can predicate a property of an object without thereby believing the object to have the property so predicated. To borrow a nice phrase from Wayne Davis (2003, pp. 332), predications, in the sense I intend, are “attitudinally neutral representations". ${ }^{23}$ There are at least two ways in which a

\footnotetext{
22 It is perhaps worth pointing out, however, that the occurrence of demonstratives in utterances puts some pressure on propositionalists to admit that utterances may often be primarily true or false. In a Davidsonian spirit, Lepore and Ludwig (2007) claim that "There is ... a sense in which the ultimate bearer of truth and falsity for ... sentences [with demonstratives] must be seen as the speech act in which the sentence is used" (p. 116).

23 For Davis, it is thoughts, not predications, that are attitudinally or cognitively neutral. Emphasizing the act-object ambiguity in 'S's thought that p' (pp. 27, 296ff), Davis takes a thought in the relevant sense to be the object, that is, the content, of an intentional act, not the act itself. Davis goes on to propound the interesting view that thoughts (in the object or content sense) are mental event-types. Since he identifies propositions with (declarative) thoughts, it follows that propositions are, for him, event-types: "Propositions are ... types of mental events" (p. 344). Soames (2010) and Hanks (2011) have more recently (and independently of Davis) defended the same basic view that propositions are
} 
predication can be attitudinally neutral: it can be a mere, non-committal predication, standing on its own, as it were, in the sense of a mere entertaining or considering of a possible state of affairs; or it can be a non-committal component of a larger predication to which the agent is committed. Davis (p. 296) gives an example of the first way: as he puts it, I can think the thought Berlin is the capital of France without thereby thinking, that is, believing that Berlin is the capital of France. My way of putting it is to say that I can predicate being the capital of France of Berlin, without endorsing or committing myself to the predication, that is, without the predication being a judgement or a belief. An example of the second way in which a predication can occur without being accepted or endorsed is the following: believing that Berlin is the capital of France if Paris is not. ${ }^{24}$ In Davis's terms, if I believe this whole conditional thought, then I must at least think the constituent thought Berlin is the capital of France, but I can do this without thinking, that is, without believing, that Berlin is the capital of France - I may, after all, quite naturally believe that Berlin is not the capital of France! In other words, in order to believe the whole conditional thought, the constituent thought contained in the consequent must occur to me, even if I do not believe it. In my terms, what we have are three predications, only the last to which I am committed: the predication of not being the capital of France of Paris, being the capital of France of Berlin, and $\lambda x \lambda y[$ if $x$ then $y]$ of the first two

\footnotetext{
types of mental events. For Soames they are cognitive event types in which an agent predicates something of something, where these cognitive events of predication are, like Davis's mental event types and my predication act-types, attitudinally neutral representations. If I understand Hanks' view correctly, propositions for him are types of acts of assertion, and so are not, contrary to the view of Davis and Soames, attitudinally neutral representations (Hanks 2011, p. 14). To the best of my knowledge, the first philosopher explicitly to propose the basic idea that propositions are types of mental events was John Wisdom (Wisdom 1934, ch, 11, esp. pp. 198-201). Since Wisdom effectively takes propositions to be types of judgments (he calls them "abstractions from" sets of token judgments), he, like Hanks, views them as not attitudinally neutral. Because both Wisdom and Hanks view propositions as attitudinally non-neutral representations, namely, as judgment/assertion types, they face the shared-content/different-attitude problem that scuppers Jubien's equally attitudinally non-neutral belief-properties (and causes more limited damage to Merricks (2009), as mentioned above in note 18). Be that as it may, despite these differences, Wisdom, Soames and Hanks all agree with Davis that propositions are identical with mental event types of some kind or other. Soames says, e.g., that "the proposal makes a plausible claim about what propositions really are, rather than merely choosing abstract structures, about which there is bound to be some arbitrariness, to play the role of propositions" (2010, p. 100; cf. Hanks 2011, p. 18). I have so far been assuming the contrary, on Jubien's behalf, that the predication act-types I suggest should replace Jubien's belief-properties are not to be identified with propositions. In the final section (VI) below, I confront the question whether predication act-types should in fact be identified with propositions.

24 The point, of course, goes back to Frege — see, e.g., Frege (1919/1977), p. 34 — and was famously used by P. T. Geach (1965) against expressivism. Cf. Davis on the possibility of simultaneously thinking (in the act sense) both $p$ and not- $p$ when thinking (in the object sense) 'It is tautological that $p$ or not-p' (2003, p. 297).
} 
predications. The suggestion, then, is that (merely) to think the thought $o$ is $F$, or (merely) to entertain the proposition that $o$ is $F$, is to predicate $F$ of $o .{ }^{25}$ Since predications are attitudinally neutral they do not encounter the third "sharedcontent/different-attitude problem" that defeated the belief-property theory.

Summing up, predications can order (would-be) propositional constituents, can possess all the properties maintained by propositionalists to be possessable by propositions ${ }^{26}$, and can serve as sharable contents for different attitudes.

With this behind us, let us return to Jubien. He claims that without propositions, "Truth is now seen as a property that applies in the first instance to our propositional representations, whether they occur only in our thought or also in linguistic (or other) expressions of our thoughts" (p. 59). Jubien does not explain exactly what he means by "propositional representations" or how they are related to intentional-properties, such as belief-properties, hope-properties and the rest. More important for present purposes, however, is the fact that, whatever the explanation, the intuitive validity of the inference we last looked at - argument (F) above - crucially turns on one and the same thing being both a bearer of truth (in the second premise) and what the subject believes (in the first premise). So, if truth is a property of a "propositional representation" then (if the inference really is valid) it must be this same propositional representation that the subject believes, or at least the ascription of which is somehow involved in the belief report. But up until now we have been understanding belief reports like the first premise, not as involving ascriptions of propositional representations - which would anyway be incomplete because it leaves out belief - but as the ascription of belief-properties. So in order to provide an account of the formal validity of the inference (F) Jubien is going to have to rewrite the first premise, 'Hillary has the belief-property believing being a dog to be subextensive to barking', in terms of propositional representations and belief (assuming that the contrary re-writing of the second premise in terms of belief-

\footnotetext{
25 A cognitively neutral predication of property $F$ of object $o$ can of course be expressed in language by saying or uttering or writing down the sentence ' $O$ is $F$ ', because uttering/writing this sentence is not the same thing as asserting it/assenting to it (cf. Davis, p. 323). Just as I cannot believe $o$ is $F$ without having predicated $o$ of $F$, because the former entails having done the latter (but not viceversa), so too I cannot assert/assent to ' $O$ is $F$ ' without having uttered/written (or otherwise produced) ' $O$ is $F$ ', because doing the former entails having done the latter (but not vice-versa).

26 Except of course for the property of being a proposition! I discuss whether predication act-types really just are propositions by another name, and hence, whether they do possess the property of being a proposition, below in section VI.
} 
properties is not in the cards for the reasons given above). Jubien has not shown how to do this, and while it can probably be done, it threatens to undermine the unity of the property theory. For it now looks like the property theory is committed to giving an account of the logical form of belief reports when they appear in inferences involving the predication of truth (and other properties) to what is believed that is different from the account given when they appear in inferences involving other quantified belief reports. In the former case, propositional representations (plus belief in those representations) will be invoked whereas in the latter belief-properties will be. This proposal fares badly compared to the simple unified account delivered by propositionalism. $^{27}$

Moreover, it will not work anyway, for there are single belief reports that quantify over what is believed at the same time as predicating truth (or other properties) of it - for example, 'Everything Maggie believes is true'. And of course there is a range of intuitively valid arguments that involve such belief reports. Consider, for example:

(I)

Everything Maggie believes is true.

Maggie believes that Philip is reading.

Therefore, it is true that Philip is reading.

Is this to be re-written, and ultimately symbolized, in terms of belief-properties or in terms of propositional representations? Jubien does not consider the matter and it is not entirely clear from what he does say how he would handle these types of intuitively valid arguments. Two things are clear, however. First, a unified account is not an option, it is a necessity - on pain of the validity of arguments like this falling outside the scope of the property theory, thus rendering its scope smaller than that of propositionalism and thereby inferior to it. Second, the unity should be sought in the direction of propositional representations rather than in that of belief-properties.

I suggest that predication act-types are a good way of developing a unified account in the right direction, for, as I have said, predication can be seen as a kind of

27 As Wayne Davis pointed out to me, Jubien also faces the question why these "propositional representations" are any less objectionable than propositions and, moreover, why they are not propositions. I try to explain both in the final section below. 
representation: if I predicate a property of an object I thereby represent the object as having that property. So I think should Jubien should abandon the property theory in favour of what I shall henceforth call the predication theory or predicationism.

As we saw in the discussion of the property theory (section III), since beliefproperties were the referents of singular terms and the values of variables, the symbolization of quantified belief reports required a two-place predicate ' $H$ ' ('has'), taking as arguments a believer and a belief-property, and a one-place predicate ' $B$ ' ('is a belief'), taking a belief-property as argument. Embedding the new predication theory with this logical framework, an initial suggestion is to keep ' $B$ ' but replace ' $H$ ' with ' $P$ ' for the transitive verb performs holding between subjects and predication act-types. Letting ' $h$ ' and ' $b$ ' again stand for Hillary and Bill, we replace the earlier belief-property symbolization (E) from section III of inference (A) involving Hillary and Bill, as follows:

(J)

Php \& Bp

$\forall x[(P h x \& B x) \rightarrow P b x]$

Therefore, $P b p \& B p$.

Predication is here treated as a mental act that hooks the would-be propositional relata together, as Jubien puts it, and which can then result in any number of different kinds of attitudes: it might result in a belief, a desire, a fear or what have you — all of which is just another way of saying that cognitively sophisticated creatures are capable of representing things to themselves and then taking up a variety of attitudes to the representations thus formed. In order to symbolize the argument, 'Hillary fears that all dogs bark; Bill fears everything Hillary does; therefore, Bill fears that all dogs bark', all we need to do is swap the ' $B$ ' for ' $F$ ' which stands for the property being $a$ fear.

Unfortunately, this will not do, because the first premise of $(\mathrm{J})$ does not entail that Hillary actually believes being a dog to be subextensive to barking. To be sure, she may perform the predication act-type predicating subextensiveness of being a dog 
and barking, and this predication act-type (which she performs) may have the property of being a belief — but that Hillary herself has this belief, that is, that she believes being a dog to be subextensive to barking, does not seem to follow from these two facts. ${ }^{28}$

We might try applying the predicate ' $B$ ', not to the predication act-type $p$, but to Hillary's performance of $p$. As things stand now, unfortunately, this is not possible, because ' $P h p$ ' is a statement and not a singular term, so that ' $B(P h p)$ ' is not well formed. If we really want to pursue this line, we will have to replace the statement 'Php' with a singular term to which the predicate ' $B$ ' can be attached. This suggests that some kind of nominalizing is required. Since we also crucially need to be able to quantify the position occupied by ' $p$ ', we also need to be able to quantify into the singular-term nominalization. It looks, then, like we will need to appeal to a function, specifically a binary function $f(x, y)$, mapping cognitive agents and predication acttypes onto performances of tokens of those act types by those cognitive agents. The predicate ' $B$ ' can then legitimately be attached to the function symbol and the latter's argument positions quantified. Let us take ' $\operatorname{per}(x, y)$ ' as the singular function term in question, so that ' $\operatorname{per}(a, b)$ ' is the nominalization of ' $P a b$ ' (' $a$ performs $b$ '), namely, ' $a$ 's performance of $b$ ' or 'the performance by $a$ of $b$ '. We can attach ' $B$ ' to it, giving us the well-formed ' $\operatorname{Bper}(a, b)$ ', which could be read as ' $a$ 's performance of $b$ is one of belief' or 'the performance by $a$ of $b$ is one of belief'. We can then quantify into it, if necessary, as in ' $\exists x[\operatorname{Bper}(a, x)]$ ', which could perhaps be worded as, 'There exists a predication act-type a's performance of which is one of belief'. Re-symbolizing argument $(\mathrm{J})$ along these lines, we get:

(K)

$$
\begin{aligned}
& \operatorname{Bper}(h, p) \\
& \forall x[\operatorname{Bper}(h, x) \rightarrow \operatorname{Bper}(b, x)]
\end{aligned}
$$

Therefore, Bper(b, $p)$.

The premise and conclusion of $(\mathrm{K})$ effectively declare that Hilary and Bill perform predications that are not attitudinally neutral but to which they are committed, that is,

28 I owe this criticism of the current predication proposal to Wayne Davis. 
that they endorse. Since predications, like propositions and utterances, can be true and false, we can represent argument (F), from section IV above, as follows:

(L)

$\operatorname{Bper}(h, p)$

$\underline{T p}$

Therefore, $\exists x(\operatorname{Bper}(h, x) \& T x)$

The earlier argument (I) from the end of section IV, which combined quantification and truth-predication, and which caused Jubien's property theory some trouble, comes out as:

(M)

$\forall x[(\operatorname{Bper}(h, x) \rightarrow T x]$

$\operatorname{Bper}(h, p)$

Therefore, $T p$

It is obvious that many other properties that propositionalists attribute to propositions, such as being necessarily true, being plausible, being interesting, etc., and any relations between propositions, such as inconsistency and entailment, can be handled equally well in the same fashion. It seems plausible to conjecture quite generally that any $n$-place predicate applicable to propositions by the propositionalist's lights is also applicable to predication act-types. ${ }^{29}$

Before stepping back to evaluate this approach, let us consider a couple of slightly more complicated arguments, which look on their face to be grist for the propositionalist's mill. ${ }^{30}$

29 With the qualification mentioned in note 26 above.

30 Although the current approach to their logical forms (and those of the preceding inferences) will ultimately be rejected, the psychological components involving acts of predication and deployments of concepts will be preserved in the final account which acquiesces in the propositionalist's logical forms. The significance of this irony is discussed in the concluding section. 
(N)

Hillary believes that all dogs bark.

Bill believes that some dogs bark.

The proposition that all dogs bark entails the proposition that some dogs bark.

Therefore, Bill believes something that is entailed by what Hillary believes.

(O)

Hillary believes that all dogs bark.

Hillary has all the concepts in any proposition she believes.

The proposition that all dogs bark contains the concept of barking.

Therefore, Hillary has the concept of barking.

Let us first see how the propositionalist will symbolize these arguments. (N) will presumably come out on a propositional reading as follows:

(P)

Bhp

$B b q$

$p$ entails $q$

Therefore, $\exists x \exists y[x$ entails $y \&(B b y \& B h x)]$

Letting ' $\mathrm{C}$ ' stand for is contained in, ' $\mathrm{H}$ ' for having or possessing, and ' $\mathrm{w}$ ' for the concept of white, the propositionalist will symbolize (O) thus:

(Q)

$B h p$

$\forall x[(B h x \rightarrow \forall y(C y x \rightarrow H h y)]$

Cwp

Therefore, $H h w$.

The predication theorist's symbolization of $(\mathrm{N})$ might take the following form: 
$\operatorname{Bper}(h, p)$

$\operatorname{Bper}(b, q)$

$p$ entails $q$

Therefore, $\exists x \exists y[x$ entails $y \&(\operatorname{Bper}(b, y) \& \operatorname{Bper}(h, x))]$.

Replacing 'C' with 'D', which stands for is deployed in, the predicationist might formalize $(\mathrm{O})$ thus:

$\operatorname{Bper}(h, p)$

$\forall x[(\operatorname{Bper}(h, x) \rightarrow \forall y(D y x \rightarrow H h y)]$

$\underline{D w p}$

Therefore, $H h w$.

The idea behind ' $D$ ' is that a mental act of predication involves the cognitive deployment (or exercise or application) of concepts. When Hillary predicates subextensiveness of being a dog and barking she deploys (or applies) concepts of these three things. ${ }^{31}$ Her predication involves the application of concepts to the objects of the predication. ${ }^{32}$ Where the propositionalist operates with the notion of

31 Recall that we are assuming, with Jubien, that predication is de re with respect to the objects of predication. A detailed, comprehensive and empirically informed account of the application of (singular and general) concepts in de re thought, consistent with the predication theory, can be found in recent work by Tyler Burge. See, e.g., Burge (2009) and Burge (2010). In the latter Burge discusses predication explicitly. Though Burge's account is cast in a framework that assumes the existence of what he calls "propositional representational contents", it does not follow that the account is committed to propositionalism. Propositional representational content has four necessary constitutive features, according to Burge: it is truth-evaluable, it is conceptual, it figures in inference, and it contains at least one purely predicative concept, that is, (roughly) a concept which does not function to secure reference. In contrast, (non-propositional) perceptual representational content lacks all four features (although it has an analogue of the first: veridicality or accuracy conditions). There is no reason why predication act-types cannot possess these four features or in the last case appropriate analogues of them. E.g., instead of containing a concept that does not function to secure reference, a predication will involve the application or deployment of a concept that does not function to secure reference. Indeed, Burge (2009, pp. 248-49) is clear that in his view propositional representational contents are "abstract representational kinds" that "mark or help type-identify an individual's representational states, capacities, events, acts." I say a bit more about this below in section VI. 32 An act of predication may thus not be a primitive phenomenon but rather composed of two more basic acts, namely, an act of concept application and an act of reference. But this fact need not be reflected in the logical form required to explain the validity of attitude inferences. Hanks (2011) develops an account of acts of assertion according to which they are composed of more basic acts of reference and acts of predication (cf. Searle 1965, p. 226 and Searle 1969, ch. 2), the latter in turn being composed of acts of property expression and property attribution (to the object of the act of reference). While there is much in Hanks' approach that is congenial to the present one, for the reason indicated in note 23, it seems preferable to me to understand predication as cognitively neutral (as Searle supra does; see esp. Searle, 1969, p. 26) and hence purely predicative concept deployment as also neutral. As Burge (2010) emphasizes, concepts are applied not only purely predicatively, but also 
conceptual containment (within a proposition), in which the concepts contained are concepts of the objects the proposition is about, the predicationist operates with the counterpart notion of conceptual deployment (in an act of predication), in which the concepts deployed are concepts of the objects of predication. ${ }^{33}$

What should we make of this approach? Alas, it is not very satisfactory, for at least three reasons, one more fundamental than the others. ${ }^{34}$ First, there is a problem with taking (L) to represent $(\mathrm{F})$. If ' $\operatorname{per}(h, p)$ ' represents a past token predication of barking of all dogs, it may have been something $h$ believed even though he does not today believe that all dogs bark (he may have forgotten it or recently learned that some dogs are mute). Second, the proposal assumes that that for every agent and predication act-type, there is just one token of the act-type preformed by the agent. But this seems clearly wrong: an agent can predicate one and the same property of one and the same object on several different occasions and more than once during one overall train of thought (for example, in a process of reasoning, such as: 'Either $a$ is $F$ or $a$ is $G$; $a$ is not $G$; therefore, $a$ is $F^{\prime}$ ).

The third strike against the proposal cuts deeper - and, as we will see in the next section, is more dialectically significant. Succinctly put, it is this: Why not simply cut out the performance "middle-man" altogether and take belief and other intentional states to be two-place relations holding directly between subjects and predication acttypes? We can then symbolize 'Hillary believes all dogs bark' as having the logical form 'Bhp' and symbolize valid inferences in which it occurs accordingly, for example, symbolize $(\mathrm{N})$ and $(\mathrm{O})$ as $(\mathrm{P})$ and $(\mathrm{Q})$, respectively (similarly, mutatis mutandis, for other relevant valid attitude inferences). Indeed, there seems little reason not to. For one, it immediately solves the previous two problems. For another,

not-purely predicatively to secure reference (for further purely-predicative prediction). It is only notpurely predicative concepts, that is, concepts that help to determine reference, that are deployed nonneutrally, so that the concepts are not only applied to the objects of the act of reference but the properties that are the extensions of the concepts are also attributed to the those objects, in the sense that the person doing the predicating is committed to the object having the property in question. 33 The predicationist might at this point argue that there is a general pattern here on the basis of which a translation schema can be constructed: any instance of the propositionalist's schema ' $\mathrm{S} \Phi \mathrm{s}$ that $\mathrm{p}$ ' (' $\Phi$ sp'), where $\mathrm{p}$ is a proposition and $\Phi$ is a psychological verb ('believes', 'fears', etc.), can be translated into an instance of the predication theorist's nominalization schema ' $S$ 's performance of $p$ is one of $\Psi$ ' (' $\Psi \operatorname{per}(\mathrm{s}, \mathrm{p})$ '), where $\mathrm{p}$ is a predication act-type and $\Psi$ is the noun corresponding to the verb $\Phi$ ('belief', 'fear', etc.). Obvious translation schemata will be available for other kinds of propositional-attitude phenomena (e.g., 'S $\Phi$ s everything that $\mathrm{T} \Phi \mathrm{s}$ ' goes into 'Everything such that if S's performance of it is one of $\Psi$, T's performance of it is one of $\Psi$ too').

34 Wayne Davis raised these objections, though I have developed the third one differently from how he put it to me. 
the logical forms proposed by this last version of the predication theory are otiose as they are no longer motivated. Let me explain this last point. The predication theory, in both its penultimate and final forms, explicitly carried over the logical framework of the abandoned property theory and replaced belief-properties with predications in that logical framework in order to cope with the problems facing the belief-property theory. But that logical framework was required because belief-properties were fusions of attitude and content. But with predication act-types we no longer have such a fusion, as the latter are attitudinally neutral representations to which subjects can bear a variety of different attitudes, and so that particular logical framework, with its proposed logical forms, is no longer mandated. In other words, given the attitudinally neutral notion of predication, there is no reason why the intentional attitude should be seen as a property of the performance of the predication rather than being a direct relation between the agent and the predication itself. To be sure, a predication must be performed; but there is no need for this to be reflected explicitly in logical form. We thus find ourselves in the following situation. We have four desiderata or conditions of adequacy that any accommodation of "propositional phenomena" must meet. It must: (1) deliver the proper ordering of the (would-be propositional) constituents making up intentional contents (aka, the "ordering problem"); (2) allow intentional contents - whatever their exact ontological nature - to have properties such as being true/false, necessary/contingent, interesting/uninteresting, etc. (aka, the "property problem"); (3) allow intentional contents to be shared by different attitudes (aka, the "shared-content/different attitude problem"); and (4) be as simple and straightforward as possible. As we have seen, Jubien's original plural quantificational account fails to meet (1); his specific-belief-property account, while meeting (1), fails to meet (2) and (3); the predication theory cast in the logical framework of the unsuccessful belief-property theory, which I tried to development on Jubien's behalf as a development of the spirit of the belief-property theory, fails to meet (4), as well as having intrinsic problems of its own - both the latter owing to its account of logical form. The discussion therefore strongly points to the conclusion that the predicationist can best meet these four desiderata by holding that the logical form of 'Hillary believes all dogs bark', for example, is 'Bhp', as the present objection suggests. 
It will not have escaped the notice of the reader, however, that these final proposed logical forms are - glaringly and ironically — precisely those of the propositionalist! We have thus come full circle and ended up embracing the propositionalist's logical forms. But did the propositionalist not infer propositionalism on the basis of these logical forms? If so, must we not conclude that predication act-types really just are propositions by another name $?^{35}$ There was already a hint of this worry even under the assumption, clearly held by Jubien, that the predicationist's valid logical forms, if any were to be forthcoming, would necessarily be different from the propositionalists. But now it turns out that they are the same as the propositionalists. Surely this means the jig is up for the antipropositional predicationist? In short, the predicationist is at best a propositionalist in denial.

The predicationist may protest, however, that there are several prima facie reasons why we should resist the temptation to identify predication act-types with propositions. First of all, according to the predication theory, predication act-types, qua types, are simply kinds that type-individuate token acts of predication. Making reference to them serves the essentially classificatory purpose of categorizing or collecting together token acts of predication for the purposes of generalization, the kind of generalization that is required in psychological explanations and in explications of the validity of the kinds of inferences we have been looking at. ${ }^{36}$ References to, and quantifications over, predication act-types are ways of typing acttokens on the basis of the latters' content, that is, on the basis of what is predicated of what in the various token acts of predication being typed together. For example, adverting to the predication act-type predicating subextensiveness of being a dog and barking type-identifies a number of predication act-tokens on the basis of their shared

35 Just as Wisdom (1934), Davis (2003), Soames (2010) and Hanks (2011) all maintain that certain kinds of mental event types are what propositions really are. See note 23 above. Davis pressed me to discuss whether predication act-types should not simply be identified with propositions.

36 Cf. Burge, loc. cit. and op. cit., p. 248: "The abstract contents, as aspects of kinds, are essential for the explanatory and evaluative aims of [psychological explanatory] enterprises. These enterprises do depend on reference to the contents and to the states and events in the individuals. The contents mark the states and events. But these enterprises do not always clearly depend on reference to instances of contents over and above the states and events." See also Burge (2005), pp. 29-31. For further discussion of whether there are other reasons for thinking that reference to instances of contents beyond the actual states and events that have them is required, see note 47 below. 
content, that is, on the basis of the fact that they all predicate subextensiveness of being a dog and barking. There are of course lots of other ways of type-individuating acts of predication, but doing so by what they predicate of what, is a particularly important one for psychological and other explanatory endeavours. Predication acttypes, qua types, are therefore, abstract, in the sense that they are not located at any particular place or time. ${ }^{37}$ Moreover, they are abstract universals — not abstract particulars. But propositions, as propositionalists usually conceive of them - the predicationist might press - are abstract particulars, akin to numbers, functions, and sets. ${ }^{38}$ Indeed, some propositionalists identify propositions with sets (either sets of possible worlds — in the so-called "structureless" view_ or ordered sets of particulars, properties and relations - in the "structured" view). So, the predicationist might say, it is hard to see how a predication act-type or indeed any event-type could literally be a proposition. ${ }^{39}$ According to propositionalism, when $S$ believes $p$, we have two particulars standing in a relation (of believing) to each other: the first particular, $S$, is a concrete particular, which exists in space and time and has causal powers, whereas $p$ is an abstract particular, which does not exist in space and time and does not have any causal powers. This is similar to a common view of thinking about numbers. If $S$ is thinking about the number nine then there is a relation, thinking about, holding between a concrete particular, $S$, and an abstract particular, the number nine..$^{40} \mathrm{In}$ short, it seems on the face of it that types and propositions each fall into mutually exclusive ontological categories of abstract objects and hence cannot be identified.

37 As already mentioned in note 23, Wisdom (1934) viewed propositions as abstractions from token judgments. Cf. Burge (2005, p. 28) on the abstract nature of "representational content."

${ }^{38} \mathrm{Cf}$. Church (1956): "[A] proposition, as we use the term, is an abstract object of the same general category as a class, a number, or a function" (p. 26). Hoffman and Rosenkrantz (2003, pp. 55) are explicit in distinguishing (mutually exclusively) between abstract universals and abstract particulars and declaring properties and relations to be the former and sets and propositions to be the latter.

39 Thus, against Davis, who maintains that "propositions are abstract because they are types" (2003, p. 344), the predicationist will be more inclined to agree with Church (1956) and Hoffman and Rosenkrantz (2003) - see previous note - that propositions are supposed to be abstract in the same way that numbers and sets and other mathematical objects are abstract, and these latter are not abstract because they are types, because they are not types. But see below for a contrary view.

40 Notoriously, of course, this Fregean way of thinking of propositions and our relations to them raises a host of difficulties, such as how we could come into cognitive contact with them (sometimes known as one of the two "Benaceraff problems" facing the postulation of abstract objects, the other being the one mentioned in note 4 above). The predication theory does not have to face these problems whatever others it might face. 
Secondly, a type has instances or tokens, but a proposition, being a particular, does not. ${ }^{41}$ Thirdly, a predication act-type, like any event type, is the kind of thing that happens or occurs, and so is the kind of thing that takes place at a certain time in a certain place and has a certain duration - think of the type of event commonly known as a battle. But, the predicationist might say, it seems extremely odd to think of propositions as having these features; surely they are not the kinds of things that can occur somewhere in space and time and have a certain duration. Fourthly, predication act-types are the kinds of things that we perform or engage in. But again, the predicationist may aver, it is exceedingly strange to say that propositions are the kinds of things that we perform or engage in (e.g., that Hillary and Bill performed the same proposition). For these reasons, the predicationist might try to argue that we should be loath to identify predication act-types with propositions.

In the end, however, the predicationist should probably be prepared to admit that these considerations, while important in understanding the nature of predication acttypes, are not decisive. ${ }^{42}$ For a propositionalist may well maintain that none of the above features traditionally associated with propositions which set them off from event-types - that they are abstract particulars and do not have instances that occur in space and time and that have duration and are performed - are essential to propositions as propositionalists understand them. On the contrary, the propositionalist might simply maintain that the above arguments in favour of the predication theory should be seen as arguments for the view that propositions in the relevant sense are abstract universals (and therefore can be exemplified in space and time, etc.); the fact that some, perhaps even most, philosophers think they are abstract

41 Cf. Hoffman and Rosenkrantz (2003): "there are ... abstracta that are not exemplifiable, for example, sets and propositions" (p. 49) and "While there are different instances of one or more sentence types that express the same proposition, the proposition itself does not have instances, and so is a particular" (p. 55).

42 Cf. Soames (2010, p. 103), who does not find the idea that propositions occur and have instances incoherent or "disqualifyingly bizarre." Davis, too, is readily prepared to admit that "... 'proposition' does not have a token sense in conventional usage. In no sense is there more than one proposition that the sky is blue" (loc. cit.). However, if I understand Jeshion's (2008, p. 411) and Siebel's (2008, p. 422) criticism of Davis's idea that representational contents (propositions) are literally types of mental events - rather than just ways of typing the mental events that have those contents - it strikes me that they can be met by dropping the idea of representational contents as self-standing abstract types to which agents can stand in relations, since their criticisms seem to rely on this assumption. As Burge suggests (see notes 31 and 36 above), all that we need commit ourselves to is the idea that representational contents of representational acts and events are aspects of those kinds of events, aspects that can be used to type-individuate those kinds of acts and events. For what it is worth, I cannot see that this issue significantly affects one way or another the rest of Davis's impressive theory. 
particulars (and therefore not exemplifiable, etc.) notwithstanding. ${ }^{43}$ The propositionalist may fairly back this up further by pointing out that the claim that propositions are traditionally grouped with sets and numbers rather than properties and relations does not cut much ice in face of the fact that some philosophers have argued that set and numbers are - again, tradition notwithstanding — actually universals! ${ }^{44}$ So, it does not seem anyway to follow that aligning propositions with abstracta such as numbers and sets aligns them with particulars rather than universals.

But does all of this mean that the dispute between propositionalists and antipropositionalists is a verbal dispute? Is the concept of a proposition so minimal that it is the kind of thing that could turn out to be virtually anything that met a minimal and relatively metaphysically neutral set of conditions, and in particular, could turn out to be something that few would deny exist, such as certain types of sentences or certain types of mental events (or equivalence classes of tokens of sentences or mental events, under some suitable relation)? It would seem somewhat incredible that this should be how the more-than-a-century-long debate over the nature and existence of propositions that characterizes a significant part of the history of analytic philosophy — a debate involving Bolzano, Meinong, Frege, Moore, Russell, Ryle, Carnap, Church, Quine, Davidson, Schiffer, Jubien, et. al. — should be understood. Quine (1956, p. 186) famously derogated propositions (actually, intensions generally) as "creatures of darkness," and invited the reader to rejoice in their exorcism. Schiffer (1987, p. 49) has said he used to concur that their exclusively nocturnal existence made them hard to believe in. But Quine believed in the existence of sentences (and in equivalence classes of them) and Schiffer believes in the existence of mental events (and equivalence classes of them). So what is going on here? Clearly, Quine and Schiffer both have a fixed idea of what kinds of things can be propositions and

\footnotetext{
43 This issue is potentially dialectically important, for if Jubien's arguments against propositions (mentioned in passing in note 4 above) depend on propositions having these features (e.g., depend on propositions being abstract particulars) then the arguments can be side-stepped by dropping the assumptions that they have these features (e.g., by dropping the assumption that they are abstract particulars). But if Jubien's own anti-propositional view were premised on his attack on propositions understood in this way, then his own view would be in danger of losing much of its motivation. Fortunately, Jubien's arguments against propositions are not premised on them having these features. As I explain below, the arguments are targeted against what Jubien calls "Platonic propositions" whose most conspicuous feature is their alleged mind-independence. 44 Bigelow (1990) argues that sets are universals and E. J. Lowe (1993) that numbers are. Davis (2003, p. 315$)$ suggests in passing that sets are universals.
} 
what kinds of thing cannot and presumably neither sentence types nor mental event types (or equivalence classes of tokens of them) can. This strongly suggests that what is going on is that there are two broad conceptions of propositions, a metaphysically heavyweight conception and a metaphysically lightweight conception, and that those who use the validity of the kinds of inferences we have been discussing to support the existence of propositions often trade on a failure to distinguish between the two conceptions. The relevance of this to present purposes is that it is only on the metaphysically lightweight understanding of a proposition that predication act-types can plausibly be understood to be propositions.

The metaphysically lightweight conception is essentially a functional-role conception, according to which propositions are the kinds of things that play certain logico-semantic explanatory roles (cf. King 2007, pp. 1ff; Loux 2006, p. 122). Sometimes these roles are kept to the barest minimum. The logician W. E. Johnson (1921) of determinable-determinate fame, for example, introduced propositions as no more than "that of which truth falsity can be significantly predicated" (p. 1). More recently, Mark Richard (1990, p. 7) has used the term 'proposition' to designate simply whatever 'that'-clauses in attitude ascriptions name. Similarly, Paul Horwich (1998) has said of 'that'-clauses construed as singular referring terms in attitude ascriptions, that "it is a matter of stipulation to call the entities to which they refer, "propositions"' (p. 82). I take it as obvious that both Richard and Horwich would agree that the referents of 'that'-clauses are also thing to which truth and falsity can be predicated. Now, if all one means by the term 'proposition' is whatever is both true and false and is the referent of 'that'-clauses (and fulfils other relevant functional roles) then predication act-types (as well as Jubien's "propositional representations," whatever they are supposed to be exactly) are indeed propositions, because according to the predication theory they play the logico-semantic functional roles definitive of propositions.

The metaphysically heavyweight conception goes beyond the purely functional conception by including a number of metaphysical theses about the nature of the entities, the "propositions," that play these functional roles. The most commonly cited metaphysical features are those that are also commonly attributed to numbers and other abstract objects, namely, mind- and language-independence and eternal and necessary existence. Chisholm, for example, has said that "If we take the term 
'proposition' in what may now be said to be its correct philosophical sense, we may say that this term, if it refers to anything, refers to an abstract object existing in every possible world" (Chisholm, 1976, p. 122; cf. Davis 2003, p. 344 and Loux 2006, p. 126). Here we shall restrict ourselves to focussing on mind-independence, however, which is of course a crucial feature of the traditional view of propositions upheld in the early days of analytic philosophy by its anti-psychologistic and anti-AbsoluteIdealist heroes, Frege, Moore and Russell. ${ }^{45}$ This is arguably the most commonly cited and least controversial metaphysically heavyweight feature of propositions and (as we shall see shortly) is precisely the target of Jubien's attack on propositions. But if this is what one means by a proposition, then it is not at all clear that predication act-types are propositions, for it is not at all clear that predication act-types are mindindependent. ${ }^{46}$ This issue is part of the larger dispute between Platonists about types (according to which there can be untokened types) and Aristotelians about types (according to which there cannot be untokened types). Fortunately, that debate need not be settled here, for present purposes are served by noting that it is not necessary for predication act-types to be mind-independent in order to be invoked to explain the validity of inferences involving attitude ascriptions, and that is all predication acttypes can reasonably be demanded to do in the present context. All that is required for them to explain validity, and fulfil other commonsense and scientific explanatory endeavours, is that they be abstract in the sense of not being located in any particular place and time (cf. Burge, 2005, p. 28). It is not further required that they be mindindependent. $^{47}$

45 "Propositions, for Moore and Russell, are objective complexes composed of simple concepts which have an ontological status independent of the minds that apprehend them" (Stevens 2006, p. 101). As Stevens discusses, Russell goes on to repudiate this circa-1900 view and embrace a form of psychologism.

46 Cf. King (2007), who develops a view according to which propositions are certain kinds of facts that are (inter alia) "brought into existence by conscious creatures and represent other things (have truth conditions) because of the actions of conscious creatures," so that "Had there been no conscious creatures, there would have been no propositions representing anything" (p. 136).

${ }^{47}$ This is not to say that further reasons, independent of explaining the validity of attitude inferences, may not be adduced in support of the Platonic view that predication act-types are mind-independent. Wayne Davis asked, e.g., "Aren't there infinitely many predication act-types that have not been and never will be performed? (Given any two predication act-types, isn't there a third type that is their conjunction and a fourth that is their disjunction? That is enough to generate an infinity of untokened act-types)" (personal communication; cf. Davis, 2003, pp. 316f). I confess that I am strongly inclined to answer "No" to these questions, as I cannot see that it incurs very high metaphysical costs. Indeed, if the power to order (would-be) propositional constituents into representational unities with truth conditions resides in the (linguistic and non-linguistic) token intentional activities of cognitive agents, as the predicationist holds, it is hard to see how there can be untokened representation types and so 
Often, however, the intuitive validity of those arguments is presented as alleged support for the existence of a metaphysically heavyweight conception of propositions, in particular, one according to which they are mind-independent. Schiffer (2003), for example, has said that if we agree that the 'that'-clauses in attitude attributions are singular terms (because this logical form is the best explanation for the intuitive formal validity of the inferences in question) then one of the things that "it would seem, we can straightaway say ... about ... the referent of the that-clause singular term" is that it is "mind- and language-independent," from which he concludes that the "things believed are what philosophers nowadays call propositions: abstract, mind- and language-independent entities ..." (p. 14; cf. Loux 2006, p. 126). Similarly, two recent co-authors begin by characterizing propositions purely functionally in a metaphysically neutral way — as "the sharable objects of belief and other intentional attitudes, the contents of these thought-states and of assertion and other speech acts, the common meanings of utterances from different languages, and the fundamental bearers of truth, necessity, aprioricity, and other aletheic and modal and epistemic properties" (Armour-Garb and Woodbridge, 2012 p. 635) - but then go on to say that "the inferential practices displayed in arguments [like the ones we have been examining here- $-\mathrm{SC}$ ] are easily regimented into firstorder logic, if we take the claims involved to traffic in a domain of mind- and language-independent entities" ( p. 636), thereby sliding into a more-than-purelyfunctional metaphysically heavy-duty conception. ${ }^{48}$ In an excellent discussion of precisely this issue, however, Iacona (2003) has shown in detail that one cannot infer

untokened predication act-types (see below for more discussion of this). To the related question whether "The thought [that two plus two is four] was true a billion years ago as it is today" (Davis, 2003, p. 317), I prefer the simple and straightforward answer, "No, it was not true a billion years ago (even though it is true today) because (unlike today) a billion years ago there were no representations, and truth is a property of representations." This is consistent with maintaining that a billion years ago two plus two was four. We simply need to distinguish, as King $(2007$, p. 71) puts it, between the claim that "nothing was true in the remote past" and "things weren't a determinate way in the remote past" and be careful not to confuse the two (which Frege and many others seem to have done). Similarly, as Jubien says in giving a negative response to the question whether it was true billions of years ago that stars were emitting light, "Why panic? It wouldn't follow that, billions of years ago, stars weren't emitting light. They were. The properties of being a star and emitting light were indeed coinstantiated in those otherwise dark times" (2001, p. 60). More sophisticated and theoretically-driven contrary accounts, according to which it was true that two plus two is four and that stars emitted light, in the distant past, and that these thing are true, in possible worlds devoid of representations, can be found in Iacona (2003), Jubien (loc. cit.), King (2007, pp. 76ff), and Soames (2010, pp. 104f).

48 Unlike many, Bealer (1982, pp. 24-29) is careful to distinguish clearly between the claim that treating 'that'-clauses as singular terms gives the best account of validity and the claim that their referents are propositions. Obviously, however, drawing this distinction implies that he is not, like Richard and Horwich, stipulating that propositions are whatever the referents of 'that'-clauses are. 
the existence of metaphysically heavyweight propositions, such as allegedly mindand language-independent entities, merely from data involving our linguistic and inferential practices, including attitude inferences. For example, as I have already indicated, it does not follow simply from the fact that there must be something to serve as the common content of Hillary's and Bill's belief and Maggie's fear that all dogs bark, and the interesting and plausible and contingent falsehood that all dogs bark, that this common thing — call it a "proposition" if you like - must be capable of existing in the absence of any thinkers or language users (let alone that it must exist eternally and necessarily). ${ }^{49}$ Put another way, it does not follow from the fact that the best way to symbolize formally the validity of attitude inferences is to take 'that'-clauses as referring singular terms, that those singular term refer to mindindependent entities; therefore, in so far as the propositionalist construes propositions as mind-independent entities, the fact that the validity of those arguments is best explained by taking 'that'-clauses as singular terms does not support propositionalism. $^{50}$

Let me conclude by connecting what we have just been saying with Jubien's prior attack on the existence of propositions, alluded to at the outset. It is necessary anyway to assure ourselves that Jubien's arguments against the existence of propositions - which I am assuming by definition the predicationist accepts, since they are part of the motivation for predicationism - do not also cast doubt on the existence of predication act-types. Jubien's attack on propositions is clearly aimed at a metaphysically loaded conception, a conception according to which propositions are mind-independent entities. He calls them "Platonic propositions," which "are held to exist independently of minds and the spatio-temporal realm" (p. 47), and he associates the view he is attacking with Frege (though he could easily also have associated it with Moore and the early Russell). Now, both of Jubien's arguments

49 Iacona (2003) also argues persuasively against several further theoretically sophisticated arguments purporting to establish the existence of metaphysically loaded conceptions of propositions on the slim basis of the premise that propositions are the referents of 'that' clauses (he shows, e.g., that Bealer's (1993) modal argument for the necessary, and hence mind-independent, existence of propositions is question-begging).

50 If, contrary to orthodoxy, Rosefeldt (2008) is right that 'that'-clauses are not in fact singular terms, then we can reformulate this as follows: the fact (if it is a fact) that the validity of attitude inferences is best explained by taking 'that'-clause expressions to have single entities as their semantic values, and interpreting the quantification over these entities as a form of "non-nominal" quantification, does not show the entities in question to be mind-independent, and hence, to be propositions on one very common understanding of what propositions are. 
against propositions ultimately come down to the same thing, namely, his chief claim that nothing mind-independent could order the propositional constituents of propositions in the right way or, even more fundamentally, could have any order there in the first place (Jubien 2001, pp. 53-4, 57). For Jubien, both of these strikes against "Platonic," that is, mind-independent, propositions reduce to the claim that such entities, by very dint of being mind-independent, cannot be representational. ${ }^{51}$ As he says, "it's implausible to think that any genuine Platonic entity could represent off its own cuff. Representation is an 'intentional' or 'outer-directed' relation. ... [it] is ultimately the business of beings with intentional capacities, in short, thinkers" (p. 54). Since predication act-types are obviously types of thing that are intrinsically representational, because they are precisely types of intentional mental events, Jubien's arguments against propositions do not also apply to them. Can we nevertheless call mind-dependent predication act-types propositions, if we want to? Yes - if by 'proposition' you mean merely something defined functionally as whatever plays certain roles. No - if by 'proposition' you mean Platonic proposition. ${ }^{52}$ None of this, of course, establishes that the predication theory is true and that Platonic propositionalism is false — but it does, I think, at the very least, put the ball squarely in the Platonic propositionalist's court, in so far as the latter has been construing the intuitive validity of attitude inferences as providing support for that view. Non-Platonic functionalists about propositions are of course free to call predication act-types propositions, for whatever that is worth to them. ${ }^{53}$

\section{References}

Armour-Garb, Bradley and James A. Woodbridge. 2012. 'The Story about Propositions', Noûs 46(4): 635-674.

\footnotetext{
51 In the only critical discussion of Jubien's attack on (Platonic) propositions that I know of, King (2007) concedes this fundamental point to Jubien, noting that it is sufficient for his purposes that it is consistent with his view of propositions as (special kinds of) facts. See note 46 above.

52 So far as I can see, there is little substantial difference between Jubien (2001) and (Soames 2010) on the question of the existence of propositions. They both agree that representational powers rest squarely on the shoulders of cognitive agents. They simply differ over how they describe their common position. Jubien prefers to describe it as one that rejects propositions while Soames prefers to describe it as one that accepts but reconceives propositions.

53 I am extremely grateful to Wayne Davis for some challenging but constructive criticisms, and for patient and encouraging advice and suggestions, all of which led to significant improvements to the original manuscript.
} 
Ayer, A. J. 1940. Foundations of Empirical Knowledge. London: Macmillan.

Bealer, George. 1982. Quality and Concept. Oxford: Clarendon Press.

Bealer, George. 1993. 'Universals', Journal of Philosophy 60 (1): 5-32.

Benaceraff, Paul 1965. 'What Numbers Could not Be', Philosophical Review 74 (1): $47-73$.

Bigelow, John. 1990. 'Set are Universals', in A. D. Irvine (ed.) Physicalism in Mathematics. Dordrecth: Kluwer, pp. 291-305.

Burge, Tyler. 2010. 'Steps Toward Origins of Propositional Thought', Disputatio 4 (29): 39-67.

—. 2009. 'Five Theses on De Re States and Attitudes', in Joseph Almog and Paolo Leonardi (eds.) The Philosophy of David Kaplan. New York: Oxford University Press.

— 2005. Truth, Thought, Reason. Essays on Frege. Oxford: Clarendon Press.

Chisholm, Roderick. 1976. Person and Object. London: George Allen and Unwin.

Chisholm, Roderick. 1981. The First Person. Minneapolis: University of Minnesota Press.

Church, Alonzo. 1956. Introduction to Mathematical Logic. Princeton: Princeton University Press.

Crawford, Sean. 2008. 'Quantifiers and Propositional Attitudes: Quine Revisited', Synthese 106: 75-96.

Davis, Wayne A. 2003. Meaning, Expression, and Thought. Cambridge: Cambridge University Press.

Feit, Neil. 2008. Belief about the Self. A Defense of the Property Theory of Content. New York: Oxford University Press.

Field, Hartry. 1978. 'Mental Representation', Erkenntnis 13: 9-61.

Frege, Gottlob. 1919. 'Negation'. In Logical Investigations, P. T. Geach (ed.). New Haven: Yale University Press, 1977. 
Fodor, Jerry A. 1978. 'Propositional Attitudes'. Reprinted in J. Fodor, Representations. Brighton, Sussex: The Harvester Press, 1981.

Geach, P. T. 1965. 'Assertion', Philosophical Review 74 (4): 449-465.

Hanks, Peter. 2011. 'Structured Propositions as Types', Mind 120 (477): 11-52.

Hoffman, Joshua and Gary S. Rosenkrantz. 2003. 'Platonistic Theories of

Universals', in Michael J. Loux and Dean W. Zimmerman (eds.) The Oxford Handbook of Metaphysics. Oxford: Oxford University Press.

Horwich, Paul. 1998. Meaning. Oxford: Clarendon Press.

Iacona, Andrea. 2003. 'Are there Propositions?', Erkenntnis 58 (3): 325-351.

Jeshion, Robin. 2008. 'Thoughts and Ideas', Philosophical Studies 137: 409-415.

Johnson, W. E. 1921. Logic, Part 1. Cambridge: Cambridge University Press.

Jubien, Michael. 2001. 'Propositions and the Objects of Thought', Philosophical Studies 104(1): 47-62.

Jubien, Michael. 2009. Possibility. Oxford: Clarendon Press.

King, Jeffrey C. 2007. The Nature and Structure of Content. New York: Oxford University Press.

Lepore, Ernst and Kirk Ludwig. 2007. Donald Davidson's Truth-Theoretic Semantics. Oxford: Clarendon Press.

Lewis, David. 1979. 'Attitudes De Dicto and De Se', Philosophical Review 87: $513-545$.

Loux, Michael. 2006. Metaphysics. A Contemporary Introduction, 3rd ed. London: Routledge.

Lowe, E. J. 1993. 'Are the Natural Numbers Individuals or Sorts?', Analysis 53 (5): $142-146$

Merricks, Trenton. 2009. 'Propositional Attitudes?', Proceedings of the Aristotelian Society 109: 207-232. 
Moltmann, Fredericke. 2003. 'Propositional Attitudes without Propositions', Synthese 135: 77-118.

Moore, G. E. 1953. 'Propositions'. In Moore, The Central Problems of Philosophy. London: George Allen \& Unwin.

Moore, Joseph G. 1999. 'Propositions, Numbers, and the Problem of Arbitrary Identification', Synthese 120 (2): 229-263.

Prior, Arthur. 'Oratio Obliqua', Proceedings of the Aristotelian Society, Supplementary Volume 37 (1963): 115-26. Reprinted in Prior, Papers in Logic and Ethics. London: Duckworth, 1976.

Quine, W. V. 1956. 'Quantifiers and Propositional Attitudes', in Quine's Ways of Paradox. New York: Random House, 1966.

— 1977. 'Intensions Revisited', Midwest Studies in Philosophy 2.

— 1986. Philosophy of Logic, 2nd ed. Cambridge, Mass: Harvard University Press.

Richard, Mark. 1990. Propositional Attitudes. Cambridge: Cambridge University Press.

Richard, Mark. 1996. 'Propositional Quantification'. In B. J. Copeland (ed.) Logic and Reality. Essays on the Legacy of Arthur Prior. Oxford: Clarendon Press.

Rosefeldt, Tobias. 2008. “"That”-Clauses and Non-Nominal Quantification', Philosophical Studies 137: 301-333.

Russell, Bertrand. 1910. 'On Truth and Falsehood'. Philosophical Essays. London: Allen and Unwin.

Schiffer, Stephen. 1987. Remnants of Meaning. Cambridge, Mass.: MIT Press.

— . 2003. The Things We Mean. Oxford: Clarendon Press.

Searle, John. 1965. 'What is a Speech Act?', in Max Black (ed.) Philosophy in America. London: George Allen and Unwin, pp. 221-239.

Searle, John. 1969. Speech Acts. Cambridge. Cambridge University Press.

Siebel, Mark. 2008. 'The Ontology of Meanings', Philosophical Studies 137: 
417-426.

Soames, Scott. 2010. What is Meaning? Princeton: Princeton University Press.

Stevens, Graham. 2006. 'Russell's Re-Psychologizing of the Proposition', Synthese 151: 99-124.

Stich, Stephen. 1983. From Folk Psychology to Cognitive Science. The Case Against Belief. Cambridge, Mass: MIT Press.

Wisdom, John. 1934. Problems of Mind and Matter. Cambridge: Cambridge University Press. 